\title{
Perancangan Video Pengenalan Objek Wisata Di Pulau Kalok Dengan Pendekatan Sinematik
}

\author{
Jimmy Pratama ${ }^{1}$, Sutarto Wasatan ${ }^{2}$ \\ email: jimmy.pratama@uib.ac.id \\ Sistem informasi, Universitas Internasional Batam, Batam ${ }^{1,2}$
}

\begin{abstract}
ABSTRAK
Kota Batam adalah salah satu kota yang dijadikan destinasi wisata bagi para wisatawan lokal dan mancanegara, terdapat di kabupaten Kepulauan Riau, Kabupaten Kepulauan Riau terdapat banyak pulau dan tidak begitu dikenal masyarakat luas karena minimnya penyaluran informasi, salah satunya adalah Pulau Kalok. Pada penelitian ini akan mengkaji tentang perancangan video pengenalan objek wisata dengan pendekatan sinematik, dimana video dibuat dengan alur yang sudah terkonsep dan menggunakan metode Multimedia Development Life Cycle (MDLC), alur penelitian terdapat dari enam tahap, yaitu tahap pengonsepan, melakukan perumusan konsep video yang akan dibuat, tahap perancangan, dilakukan secara rinci dan detail, tahap pengumpulan bahan, mempersiapkan bahan yang dibutuhkan saat pengambilan gambar, tahap pembuatan, dimana proyek akan dirancang, tahap pengujian, melakukan uji coba apakah sesuai seperti yang direncanakan, tahap distribusi, dimana video sudah selesai dibuat dan dipublikasikan ke dalam platform youtube. Dalam rangka memperkenalkan Objek Wisata di Pulau Kalok peneliti membuat sebuah video dengan pendekatan sinematik sehingga video menjadi media informasi yang efektif untuk mengenalkan pada masyarakat tentang keberadaan Pulau Kalok dan dapat meningkatkan minat wisatawan untuk berwisata di pulau ini.
\end{abstract}

Kata Kunci : Video Pengenalan Objek Wisata, Pendekatan Sinematik, MDLC, Pulau Kalok, Kepulauan Riau

\section{PENDAHULUAN}

Perkembangan teknologi informasi dan komputer yang maju ini telah menjadi pengaruh yang sangat signifikan dalam media pengajaran (instructional media), dengan kehadiran teknologi ini, telah mampu mengintegrasi berbagai macam kegiatan yang dapat dilakukan oleh kalangan generasi muda saat ini yang disebut dengan (CAI) computer aided instructional, yang menggunakan komputer sebagai bagian integral dari suatu sistem pembelajaran [1] . Aplikasi multimedia saat ini telah menjadikan kebutuhan bagi masyarakat. Hal tersebut menjadikan perolehan informasi bisa didapat dengan mudah di akses melalui teknologi, tetapi akan hal itu informasi tidak hanya berupa teks dan suara saja. Saat ini informasi dapat berupa video, grafik dan animasi pun telah diaplikasikan. Salah satu nya adalah YouTube, merupakan situs website yang terdapat video yang dapat diunggah oleh pengguna berisi konten kreatif dan hiburan. Dengan perkembangan TIK menjadikan interaksi antar manusia dapat mencapai lapisan masyarakat semakin terbuka, sehingga berpengaruh terhadap budaya pada masyarakat, baik positif maupun negatif [2]

Indonesia secara geografis adalah negara kepulauan dengan dua pertiga luas lautan lebih besar dari luas daratan. Keanekaragaman alam, budaya, flora dan fauna memiliki potensi untuk di perluas menjadi sebuah usaha di sektor pariwisata. Sektor pariwisata adalah salah satu bidang yang dijadikan potensi untuk dikembangkan pada zaman modern ini. Perkembangan internet sudah semakin maju, salah satunya dalam hal pemasaran suatu usaha sehingga dapat menjadi sarana promosi, menyampaikan informasi yang efektif dan efisien pada masyarakat [3]. Pulau kalok merupakan salah satu pulau yang berada di kota Batam, Kepulauan Riau. Pulau kalok sendiri tidak terlihat di dalam map sehingga kebanyakan penduduk kota batam tidak mengetahui keberadaan pulau itu sendiri. Disana terdapat perkebunan dan tambak ikan milik warga setempat. Rata-rata mata pencaharian masyarakat di sana adalah nelayan dan buruh, mayoritas warga penduduk di sana adalah suku melayu. Pulau kalok saat ini membutuhkan media informasi yang dapat memberikan informasi tentang keadaan dan aktivitas yang terjadi di sana. 
Menurut [4] film sebagai saluran komunikasi visual berpotensi mengubah gaya interaksi sosial melalui penyajian gambar nyata yang menawarkan pengetahuan dan pemahaman yang lebih dalam tentang budaya, sehingga memiliki nilai seni tersendiri, karena film tercipta sebagai salah satu karya dari orang yang kreatif dan profesional di bidangnya. Dalam pengenalan objek wisata yang merupakan penggabungan dari audio, animasi, foto dan teks yang membentuk sebuah video dengan pendekatan sinematografi yang merupakan media yang dapat menyampaikan gagasan, ide, wawasan serta perasaan untuk menghubungkan dengan pemahaman visual dengan penonton. Pendekatan sinematik menawarkan wawasan inovatif dan menggugah pola pikir terhadap dunia luar menjadi sesuatu yang dapat dimaknai.

Pengembangan media pembelajaran interaktif membutuhkan metode perangkat lunak, metode yang digunakan untuk penelitian ini MDLC (Multimedia Development Life Cycle) [5]. Menurut [6] pengembangan yang dapat memberikan sarana pengetahuan dalam pembelajaran dan menumbuhkan kreativitas, motivasi dan efektifitas.

Penulis menganalisis bahwa dengan mengenalkan objek wisata dapat menjadi media yang tepat untuk mengenalkan pada masyarakat tentang keberadaan pulau ini, dan menambahkan wawasan tentang keadaan tempat dan aktivitas sehari-hari yang dilakukan. Berdasarkan penjelasan diatas, penulis akan membuat sebuah video, dengan judul "Perancangan Video Pengenalan Objek Wisata Di Pulau Kalok Dengan Pendekatan Sinematik Menggunakan Metode Multimedia Development Life Cycle (MDLC)".

\section{METODE PENELITIAN}

Metode yang dilakukan pada penelitian ini adalah menggunakan metode Multimedia Development Life Cycle (MDLC). Metode tersebut dipilih dan digunakan dalam proses perancangan video karena dalam proses pembuatannya terdapat elemen multimedia yang digunakan seperti teks, gambar, video dan animasi sehingga dapat diolah dengan menggunakan metode tersebut. Alur penelitian terdiri dari tahapan seperti berikut :

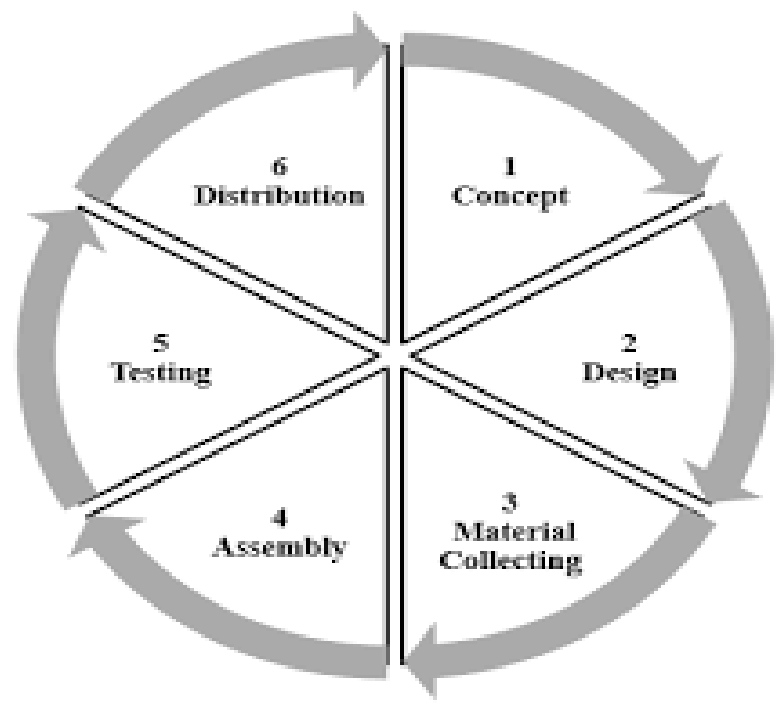

Gambar 1. Alur Penelitian

\section{A. Tahap Konsep (Concept)}

Tahap concept (konsep) yaitu melakukan perumusan konsep video yang akan dibuat. Analisa perencanaan perlu dilakukan agar mendapat gambaran seperti apa permasalahan yang dihadapi serta solusi dari permasalahan tersebut. Termasuk pengumpulan materi dan pendukung materi.

\section{B. Tahap Perancangan (Design)}

Tahap kedua dilakukan perancangan secara rinci mengenai arsitektur proyek, dan materil. Desain akan dirancang secara terperinci dan detail.

\section{Tahap Pengumpulan Bahan (Material Collecting)}

Tahap ketiga, pada tahapan ini penulis akan mencari materi apa saja yang dibutuhkan dalam dalam pembuatan video.

\section{Tahap Pembuatan (Assembly)}

Tahap keempat adalah tahapan semua proyek akan dirancang. Perancangan video didasarkan pada storyline, serta pengeditan video yang menarik agar dapat meningkatkan minat penonton.

\section{E. Tahap Pengujian (Testing)}

Testing adalah dimana perancangan dan semua data telah digabungkan. Pertama-tama akan melakukan uji coba untuk mengetahui apakah sesuai seperti yang direncanakan dan dilanjutkan dengan revisi atau koreksi. 


\section{F. Tahap Pendistribusian (Distribution)}

Tahap distribution adalah tahap dimana video sudah selesai dibuat dan disimpan dalam suatu media penyimpanan. Dalam penelitian ini evaluasi dilakukan untuk memperoleh pengetahuan mengenai efektivitas media.

\section{HASIL DAN PEMBAHASAN}

A. Concept

Pada tahapan konsep penulis sudah menentukan konsep video yang akan dirancang mulai dari alur, durasi, latar musik serta desain yang akan digunakan pada video. Video pengenalan objek wisata ini memberikan informasi tentang Pulau Kalok, konsep dalam video adalah menarik dan simpel. Simpel dari segi komposisi video yang ditampilkan berurut dari suasana alam yang asri dilanjutkan objek wisata pantai. Teknik pengambilan video dan gambar yang dibuat beda dalam setiap scene dengan kombinasi tipe shot, sudut kamera, dan pergerakan kamera. Video juga akan akan ditambahkan teks dan suara berupa instrumental. Konsep ini dirancang sebagai bentuk mempublikasikan keindahan, keasrian dan dapat dijadikan potensi sektor pariwisata.

\section{B. Design}

Pada tahap desain, perancangan ilustrasi perlu dilakukan agar mendapatkan gambaran seperti apa video akan dibuat. Perencanaan ini dapat dilakukan dengan penentuan alur storyline dengan terencana dan tersusun agar dapat dengan mudah dipahami oleh penonton. Adapun storyline yang dibuat untuk menjelaskan pada tabel berikut:

Tabel 1. Storylines

\begin{tabular}{|c|c|c|c|}
\hline No & Sequence & Scene & Durasi \\
\hline 1 & Pembukaan & 1. Logo UIB dan teks judul perkenalan untuk pembuka video & 4 detik \\
\hline \multirow[t]{3}{*}{2} & \multirow[t]{3}{*}{ Di bukit } & 2. Pemandangan sekitar bukit & 4 detik \\
\hline & & 3. Pohon sekitar bukit & 3 detik \\
\hline & & 4. Matahari terbit & 5 detik \\
\hline 3 & Di tepi jalan & 5. Pemandangan sekitar tepi jalan & 15 detik \\
\hline \multirow[t]{3}{*}{4} & \multirow[t]{3}{*}{ Di jembatan } & 6. Berjalan di jembatan berlabuh nya kapal & 12 detik \\
\hline & & 7. Menunggu kapal untuk berangkat & 6 detik \\
\hline & & 8. Menaiki kapal & 10 detik \\
\hline \multirow[t]{6}{*}{5} & \multirow[t]{6}{*}{ Di kapal } & 9. Memperlihatkan tambak ikan milik warga & 9 detik \\
\hline & & 10. Memperlihatkan air dari jarak dekat & 14 detik \\
\hline & & 11. Suasana di bagian depan kepal & 9 detik \\
\hline & & 12. Suasana di bagian tengah kapal & 17 detik \\
\hline & & 13. Memperlihatkan rumah warga & 27 detik \\
\hline & & 14. Pemandangan sekitar pulau kalok & 36 detik \\
\hline 6 & $\begin{array}{c}\text { Di depan } \\
\text { rumah warga }\end{array}$ & 15. Perkenalan diri dan wawancara singkat & 180 detik \\
\hline \multirow[t]{9}{*}{7} & \multirow[t]{9}{*}{ Di Pulau kalok } & 16. Memperlihatkan bagian depan rumah warga & 5 detik \\
\hline & & 17. Memperlihatkan kapal milik warga & 10 detik \\
\hline & & 18. Memperlihatkan bagian samping rumah warga & 5 detik \\
\hline & & 19. Memperlihatkan kayu arang & 12 detik \\
\hline & & 20. Memperlihatkan pondok sekitar pantai & 12 detik \\
\hline & & 21. Memperlihatkan suasana sekitar pondok & 19 detik \\
\hline & & 22. Memperlihatkan tempat pembakaran arang & 31 detik \\
\hline & & 23. Suasana sekitar tempat pembakaran arang & 40 detik \\
\hline & & 24. Memperlihatkan suasana sekitar tempat ternak sapi & 35 detik \\
\hline
\end{tabular}




\begin{tabular}{|c|c|l|c|}
\hline & & & \\
\hline 8 & \multirow{2}{*}{ Di pantai } & 25. Memperlihatkan burung elang sedang terbang & 5 detik \\
\cline { 3 - 4 } & & 26. Memperlihatkan pasir dan air pantai & 5 detik \\
\cline { 3 - 4 } & & 27. Memperlihatkan kapal & 7 detik \\
\cline { 3 - 4 } & & 28. Memperlihatkan bintang laut & 11 detik \\
\cline { 3 - 4 } & & 29. Memperlihatkan pohon & 11 detik \\
\hline 9 & \multirow{2}{*}{ Di kapal } & 30. Memperlihatkan pesawat & detik \\
\cline { 3 - 4 } & & 31. Suasana sekitar kapal & detik \\
\hline 10 & Penutupan & 32. Teks untuk ending video, logo UIB dan logo SI \\
\hline
\end{tabular}

\section{Material Collecting}

Pada tahapan material collecting, penulis akan mencari apa saja kebutuhan bahan pada saat proses perekaman dan bahan pada saat proses pengeditan dalam keperluan pembuatan video. Adapun proses syuting yang dibuat untuk menjelaskan pada tabel berikut:

Tabel 2. Jadwal Perancangan Video

\begin{tabular}{|l|l|l|l|l|l|l|l|l|l|l|l|l|l|}
\hline \multirow{2}{*}{ Kegiatan } & \multicolumn{2}{l}{ Sep-21 } & \multicolumn{2}{l|}{ Okt-21 } & \multicolumn{3}{l|}{ Nov-21 } \\
\hline & 1 & 2 & 3 & 4 & 1 & 2 & 3 & 4 & 1 & 2 & 3 & 4 \\
\hline Observasi & & & & & & & & & & & & \\
\hline Analisis & & & & & & & & & & & & \\
\hline Perancangan script dan storyline & & & & & & & & & & & & \\
\cline { 2 - 14 } & & & & & & & & & & & & \\
\hline Pembuatan video & & & & & & & & & & & & \\
\hline Tahap editing & & & & & & & & & & & & \\
\hline Distribusi & & & & & & & & & & & & \\
\hline
\end{tabular}

\section{Assembly}

Pada tahap pembuatan, video akan dipilih kemudian disusun sesuai dengan alur storyline yang telah dibuat, setelah itu dilakukan editing. Video akan diedit dengan menggunakan software adobe premiere pro, hasil dari tahap ini berupa video dengan ratio 16:9, dengan codec H.264 dan menggunakan cinema bar. Untuk proses edit foto, thumbnail dan gambar-gambar menggunakan adobe photoshop CS5.

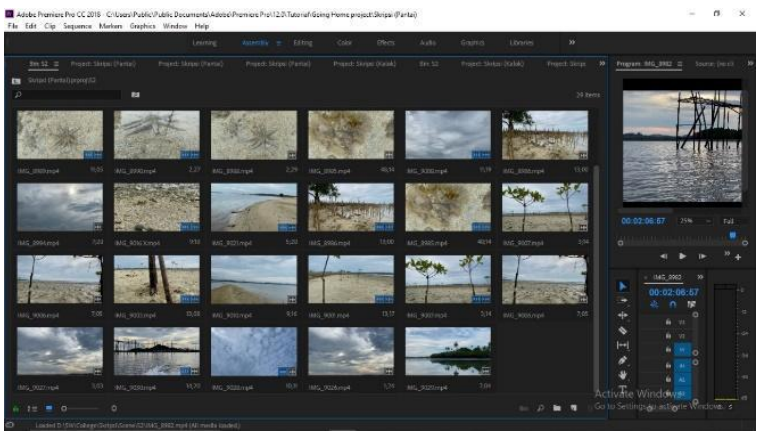

Gambar 1. Proses penyusunan video

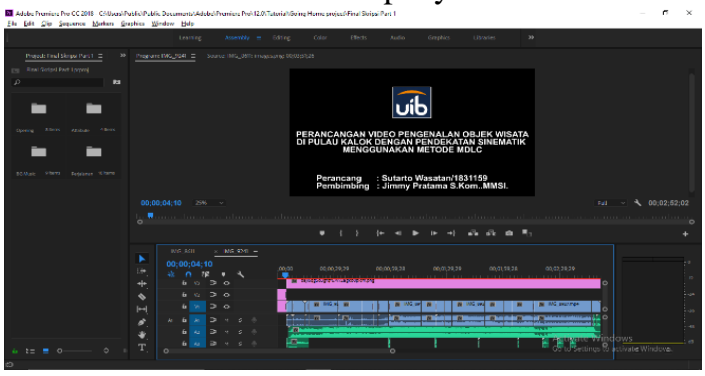

Gambar 2. Proses editing video 


\section{E. Testing}

Tahapan testing dilakukan jika tahapan pembuatan sudah selesai, pengujian dilakukan dengan menonton kembali apakah terjadi kesalahan ataupun error. Kemudian video akan dilakukan pengujian oleh dosen pembimbing dan dilanjutkan revisi atau koreksi.

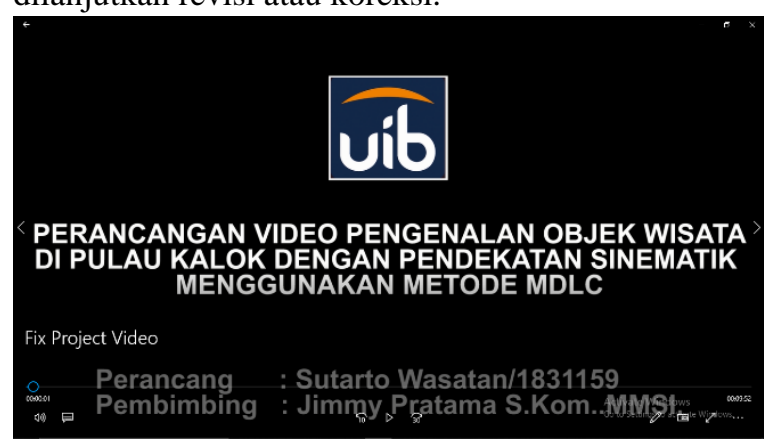

Gambar 3. Proses Implementasi video

\section{F. Distribution}

Tahap distribusi adalah dimana hasil akhir video akan diserahkan kepada dosen pembimbing untuk divalidasi, setelah valid video akan dipublikasikan ke dalam platform Youtube Prodi Sistem Informasi UIB.

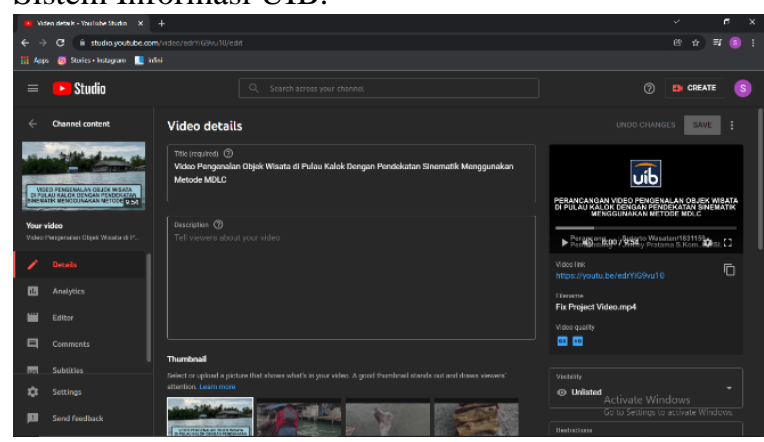

Gambar 4. Proses distribusi video

\section{Kesimpulan}

Untuk memaksimalkan pengenalan objek wisata Pulau Kalok diperlukan perancangan sebuah media promosi yang dapat memikat daya tarik wisatawan. Video diperlukan untuk memaksimalkan penyebarannya melalui media sosial. Karena saat ini media sosial efisien dan mudah untuk dioperasikan oleh para audiens. Konsep dari perancangan video ini adalah menarik dan simpel agar audiens dapat mudah memahami dan mengerti isi video. Video dibuat karena kurangnya media informasi tentang keberadaan pulau tersebut, pulau kalok sendiri tidak terlihat di dalam map, sehingga penduduk kota batam tidak mengetahui keberadaan pulau tersebut. Disana terdapat perkebunan dan tambak ikan milik warga setempat. Rata-rata mata pencaharian masyarakat di sana adalah nelayan dan buruh, mayoritas warga penduduk di sana adalah suku melayu. Pulau kalok saat ini membutuhkan media informasi yang dapat memberikan informasi tentang keadaan dan aktivitas yang terjadi di sana. Media promosi berupa video promosi dapat diterapkan dan bermanfaat bagi Pulau Kalok.

Saran Pada penelitian yang akan dilakukan kedepannya diharapkan dapat membuat film dokumenter. Video ini kedepannya diharapkan dapat di update dan diperbarui sesuai dengan perkembangan zaman. Penulis juga menyadari masih banyak kekurangan dalam perancangan video promosi ini.

\section{Daftar Pustaka}

[1] C. Herdian, "Penerapan Metode Computer Aided Instructional (CAI) Pada Aplikasi Pembelajaran Tematik Berbasis Multimedia," 2017.

[2] S. Daryanto, "Perkembangan Teknologi Komunikasi Dan Dampaknya Terhadap Kehidupan," J. Pendidik., 2017, doi: 10.1155/2015/146250.

[3] P. S. Hasugian, "Perancangan Website Sebagai Media Promosi Dan Informasi," J. Inform. Pelita Nusant., 2018.

[4] A. K. Dewi, Y. A. Piliang, Irfansyah, and A. I. Saidi, "Film Sinematik-Orkestra Sebagai Meida Komunikasi Budaya ( Studi Kasus ' Setan Jawa' Karya Garin Nugroho),” pp. 1607-1612, 2019.

[5] S. Nurajizah, "Implementasi Multimedia Development Life Cycle Pada Aplikasi Pengenalan Lagu Anak-Anak," $J$. PROSISKO, vol. 3, no. 2, pp. 14-19, 2016, [Online]. Available: https://ejurnal.lppmunsera.org/index.php/PROSISK O/article/view/18/138.

[6] H. Sugiarto, "Penerapan Multimedia Development Life Cycle Pada Aplikasi Pengenalan Abjad Dan Angka," IJCIT (Indonesian J. Comput. Inf. Technol., 2018. 